\title{
EL PROBLEMA DEL CALENTAMIENTO GLOBAL
}

¿Cómo enfrentar el calentamiento global? ¿Qué opciones de política se están proponiendo? ¿Cuáles son sus pros y contras desde el punto de vista de la generación actual y qué tensiones surgen cuando se considera el bienestar de las generaciones futuras? En las páginas que siguen se recogen distintas opiniones. Para comenzar se reproduce el ensayo de Freeman J. Dyson ("El problema del calentamiento global”, que apareció en el NYRB el 12 de junio de 2008) motivado por dos libros publicados recientemente, uno de William D. Nordhaus, A Question of Balance: Weighing the Options on Global Warming Policies, y otro editado por Ernesto Zedillo, Global Warming: Looking Beyond Kyoto. A continuación se incluye la respuesta de W. D. Nordhaus y las cartas enviadas al NYRB por Dimitri Zenghelis, miembro asociado del Royal Institute of International Affairs (Londres) e integrante del equipo que elaboró el Informe Stern sobre el calentamiento global, y de Leigh Sullivan, director de Southern Cross GeoSience. Finalmente, se publica la réplica de Dyson.

Palabras clave: calentamiento global; control de emisiones de dióxido de carbono; energía; economía del medio ambiente, The Stern Review, Protocolo de Kioto, Al Gore. 


\section{EL PROBLEMA DEL CALENTAMIENTO GLOBAL**}

\section{Freeman J. Dyson}

Comienzo este comentario [de los libros A Question of Balance: Weighing the Options on Global Warming Policies, de William Nordhaus, y Global Warming: Looking Beyond Kyoto, editado por Ernesto Zedillo] con un prólogo que describe las mediciones por las que el calentamiento global dejó de ser una especulación teórica vaga para convertirse en una ciencia precisa basada en la observación.

Hay un famoso gráfico que muestra la variación mes a mes y día a día de la concentración de dióxido de carbono en la atmósfera (véase gráfico en la página siguiente). Se trata de la evidencia más sólida y más exacta de los efectos de la actividad humana en el medio ambiente de nuestro planeta. Se le conoce vulgarmente como el gráfico Keeling porque resume el trabajo de toda una vida de Charles David Keeling, profesor de la Scripps Institution of Oceanography en La Jolla, California. Keeling midió la concentración de dióxido de carbono en la atmósfera durante 47 años, desde 1958 hasta su fallecimiento en 2005. Él mismo diseñó y fabricó los instrumentos que le permitieron realizar mediciones precisas, las que inició cerca de la cumbre del Mauna Loa, volcán inactivo situado en la Isla Grande de Hawai.

FreEMAn J. Dyson (15 de diciembre de 1923). Físico y matemático inglés, cuya obra contribuyó decisivamente al desarrollo de la electrodinámica cuántica. Fue profesor de física en la Universidad de Cornell y posteriormente en el Instituto de Estudios Avanzados de Princeton. Miembro de la American Physical Society, de la US National Academy of Sciences y de la Royal Society of London. En 1969 recibió la Medalla Max Planck y en 2000 el Premio Templeton para el Progreso en la Religión. Autor, entre otros libros, de El Sol, el Genoma e Internet: Las Tres Cosas que Revolucionarán el Siglo XXI (Editorial Debate, 2008 [1999], discusión acerca de si la tecnología moderna podría ser usada para reducir la brecha entre pobres y ricos en vez de aumentarla), Los Orígenes de la Vida (Cambridge University Press, 1999 [1986]), El Infinito en Todas Direcciones (Tusquets Editores, 1991 [1988], meditación filosófica en base a las conferencias en teología natural dictadas en la Universidad de Aberdeen).

* Comentario de Freeman J. Dyson a los libros A Question of Balance: Weighing the Options on Global Warming Policies (Yale University Press, 234 págs.), de William Nordhaus, y Global Warming: Looking Beyond Kyoto, editado por Ernesto Zedillo (Yale Center for the Study of Globalization/Brookings Institution Press, 237 págs.).

Publicado originalmente en The New York Review of Books (NYRB), Vol. 55 $\mathrm{N}^{\mathrm{o}} 10$ (12 de junio de 2008). Traducido al castellano por Alberto Ide para Estudios Públicos y reproducido en esta edición con la debida autorización del NYRB. 
CONCENTRACIÓN DE DIÓXIDO DE CARBONO EN LA ATMÓSFERA

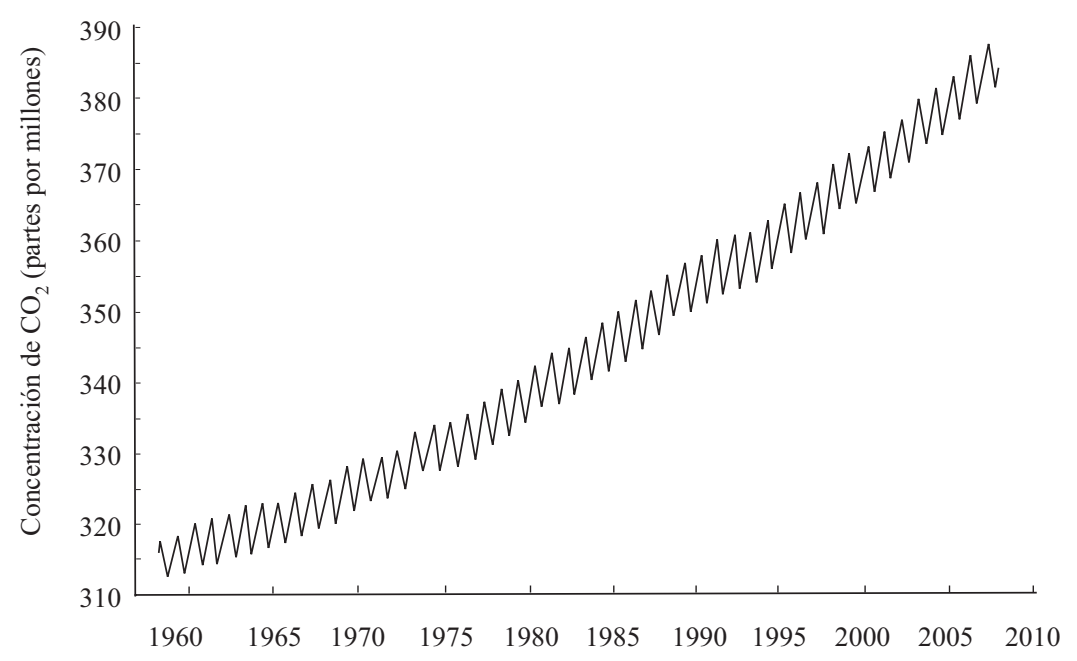

Fuente: NOAA Climate Monitoring and Diagnostic Laboratory.

Concentración de dióxido de carbono en la atmósfera

Keeling escogió ese lugar para instalar su observatorio porque el aire ambiental se encuentra alejado de cualquier continente y no está contaminado por la vegetación o por actividades humanas locales. Las mediciones han continuado después de la muerte de Keeling y muestran un aumento ininterrumpido de concentración de dióxido de carbono a lo largo de más de medio siglo. El gráfico presenta dos características manifiestas. En primer lugar, un aumento sostenido en la concentración de dióxido de carbono con el paso del tiempo, desde 315 partes por millón en 1958 hasta llegar a 385 partes por millón en 2008. En segundo lugar, una oscilación regular que revela un ciclo anual de crecimiento y disminución de los niveles de dióxido de carbono. Los niveles máximos se alcanzan cada año durante la primavera del hemisferio norte, y los niveles mínimos se registran durante el otoño del mismo hemisferio. La diferencia entre las cifras máximas y mínimas anuales es de aproximadamente 6 partes por millón.

Keeling era un observador meticuloso. La precisión de sus mediciones nunca ha sido cuestionada y sus resultados han sido confirmados por muchos otros. En los años setenta extendió sus observaciones desde el 
Mauna Loa, a 20 grados de latitud norte, hacia otras ocho estaciones en diversas latitudes, desde el Polo Sur, a 90 grados de latitud sur, hasta Point Barrow, en la costa ártica de Alaska, a 71 grados de latitud norte. En cada latitud se aprecia el mismo fenómeno de aumento sostenido en los niveles de dióxido de carbono, pero la magnitud de la oscilación anual varía considerablemente según sea la latitud. La mayor oscilación se observa en Point Barrow, donde la diferencia entre el nivel máximo y el mínimo es de alrededor de quince partes por millón. En Kerguelen, una isla en el Océano Pacífico situada a 29 grados de latitud sur, la oscilación desaparece. En el Polo Sur la diferencia entre el nivel máximo y el mínimo es de aproximadamente dos partes por millón, alcanzándose el punto más alto durante la primavera del hemisferio sur.

La única explicación plausible de la oscilación anual y su variación con la latitud es que obedece al crecimiento y descomposición estacional de la vegetación anual, en especial de los bosques caducifolios, en latitudes temperadas septentrionales y meridionales. La asimetría de la oscilación entre el Norte y el Sur se debe al hecho de que en el hemisferio norte se encuentra la mayor parte de la superficie continental y de los bosques caducifolios del planeta. La oscilación nos está entregando una medida directa de la cantidad de carbono absorbida desde la atmósfera por la vegetación en crecimiento cada verano boreal y austral, y devuelta cada invierno a la atmósfera por la vegetación que se está marchitando y descomponiendo.

La cantidad es considerable, como podemos observar directamente en las mediciones de Point Barrow. La oscilación en Point Barrow demuestra que el crecimiento neto de la vegetación durante el verano boreal absorbe cada año cerca del 4\% del total de dióxido de carbono presente en la atmósfera de alta latitud. La absorción total debe ser mayor que el crecimiento neto, pues la vegetación continúa respirando durante el verano y el crecimiento neto equivale a la absorción total menos la respiración. Los bosques tropicales en latitudes bajas también están absorbiendo y respirando gran cantidad de dióxido de carbono, el que no varía mucho con las estaciones y no contribuye mayormente a la oscilación anual.

Cuando reunimos la evidencia de las oscilaciones y de la distribución de la vegetación sobre la superficie terrestre, resulta que cada año cerca del 8\% del dióxido de carbono en la atmósfera es absorbido por la vegetación y devuelto a la atmósfera. Ello significa que el período promedio de permanencia de una molécula de dióxido de carbono en la atmósfera, antes de ser captada por la vegetación para luego ser liberada, es de aproximadamente doce años. Este hecho - la rapidez del intercambio de carbono entre la atmósfera y la vegetación — tiene una importancia fundamental para 
el futuro a largo plazo del calentamiento global, como quedará claro en lo que sigue. Ni el libro de Nordhaus ni el editado por Zedillo mencionan este fenómeno.

1. William Nordhaus es un economista de carrera, y su libro A Question of Balance: Weighing the Options on Global Warming Policies describe el problema del calentamiento global desde la óptica de un economista. Nordhaus no se ocupa de los aspectos científicos del calentamiento global, ni del detalle de las estimaciones del daño que podría causar. Supone que los detalles científicos y los daños ya están especificados y compara la eficacia de diversas políticas para asignar recursos económicos en respuesta a este problema. Sus conclusiones son en gran medida independientes de los detalles científicos. Nordhaus calcula gastos, costos y ganancias agregadas, y para ello ejecuta un solo modelo computacional que denomina DICE (siglas de Dynamic Integrated Model of Climate and the Economy).

Cada ejecución del DICE toma como información de entrada (input) una determinada política para asignar gastos año a año. Los recursos asignados se utilizan para subsidiar costosas tecnologías — por ejemplo, el secuestro subterráneo a grandes profundidades del dióxido de carbono producido en centrales eléctricas- que reducen las emisiones de dióxido de carbono, o en aplicar un impuesto a las actividades que producen emisiones de carbono. La parte del DICE relativa a la modelación climática calcula el efecto de la reducción de las emisiones en la disminución de los daños. El resultado (output) del DICE nos señala, por tanto, las consiguientes ganancias y pérdidas que se producen en la economía mundial año a año. Cada ejecución comienza el año 2005 y termina en 2105 o en 2205, entregando un panorama de los efectos de una determinada política en el curso de los próximos cien o doscientos años.

La unidad práctica de los recursos económicos es un billón* de dólares reajustados según la inflación. Un dólar reajustado según la inflación es una suma de dinero que, en cualquier momento futuro, tiene el mismo poder adquisitivo de un dólar real en 2005. En el siguiente análisis la palabra “dólar" siempre se referirá a un dólar reajustado según la inflación, con un poder adquisitivo que no varía con el tiempo. La diferencia entre los resultados de una política y otra es normalmente de varios billones de dólares, suma comparable al costo de la guerra de Irak. Las cantidades en juego, por consiguiente, son enormes.

* Trillion en el original en inglés, equivalente a un millón de millones o un billón. (N. del E.) 
El libro de Nordhaus no está destinado al lector ocasional. Está lleno de gráficos y tablas de cifras, con algunas ecuaciones esporádicas para demostrar cómo se relacionan dichas cifras. Los gráficos y las tablas muestran cómo reacciona la economía mundial frente a las distintas opciones de políticas. Para comprender esos gráficos y tablas los lectores tienen que estar familiarizados con los estados financieros y el interés compuesto, pero no necesitan ser especialistas en teoría económica. Cualquier persona con conocimientos matemáticos suficientes para hacer el balance de un talonario de cheques o para completar una declaración de impuestos debería ser capaz de comprender las cifras.

Por consideración a los analfabetos matemáticos o aquellos a quienes no les interesan los pormenores numéricos, Nordhaus incluye al comienzo del libro un capítulo no matemático titulado "Resumen para el ciudadano interesado”. Este primer capítulo contiene un resumen admirablemente claro de sus resultados y de sus consecuencias prácticas, sintetizados de tal manera que puedan ser leídos por políticos atareados y por los ciudadanos comunes, gracias a cuyos votos los primeros pueden resultar electos. Nordhaus piensa que lo más importante de cualquier política que pretenda abordar el problema del cambio climático debería ser el criterio para fijar el "precio del carbono” más eficiente, que él define como “el precio de mercado o la multa que habrían de pagar aquellos que utilizan combustibles fósiles y, por tanto, generan emisiones de $\mathrm{CO}_{2}$ ”. Señala Nordhaus:

Se puede apreciar fácilmente si alguien está tratando con seriedad o no el problema del calentamiento global por lo que dice acerca del precio del carbono. Supongamos que una figura pública se refiere con elocuencia a los peligros del calentamiento global y llama a adoptar medidas de urgencia para retardar el cambio climático. Supongamos que esa persona propone regular la eficiencia del combustible de los automóviles, o exigir el uso de bombillas de alta eficiencia, o subsidiar el etanol, o prestar apoyo a las investigaciones sobre energía solar, pero ninguna de sus sugerencias aumentan el precio del carbono. Habría que concluir que sus argumentos no son realmente serios y que en ellos no se considera el mensaje económico fundamental acerca de cómo retardar el cambio climático. En una primera aproximación, aumentar el precio del carbono es una medida necesaria y suficiente para hacer frente al calentamiento global. El resto, en el mejor de los casos, no es más que retórica y, de hecho, puede resultar perjudicial al inducir ineficiencias económicas. 
Si este capítulo fuera ampliamente leído, la opinión pública comprendería mucho mejor el fenómeno del calentamiento global y las posibles respuestas a este problema.

Nordhaus examina cinco tipos de políticas para enfrentar el calentamiento global, con muchas ejecuciones del DICE para cada una de ellas. El primer tipo consiste en mantener el actual estado de cosas (business as usual), sin restricciones a las emisiones de dióxido de carbono, en cuyo caso calcula que los daños al medio ambiente ascenderían en 2100 a unos US\$ 23 billones de dólares actuales. El segundo tipo se refiere a la "política óptima", que a juicio de Nordhaus es la más costo-efectiva, con un impuesto de alcance mundial aplicado a las emisiones de carbono, reajustado cada año para obtener la máxima ganancia económica agregada según lo calculado por el DICE. El tercer tipo es el Protocolo de Kioto, en vigencia desde 2005 y con 175 países participantes, en virtud del cual se imponen límites fijos sólo a las emisiones de los países económicamente desarrollados. Nordhaus somete a prueba diversas versiones del Protocolo de Kioto, con y sin la participación de los Estados Unidos.

El cuarto tipo de política es catalogado de "ambicioso", con dos versiones que Nordhaus denomina "Stern" y "Gore". "Stern" es la política propugnada por sir Nicholas Stern en el Stern Review" ${ }^{1}$, documento que contiene un análisis económico del calentamiento global, patrocinado por el gobierno británico. La política "Stern" impone límites draconianos a las emisiones, similares a los estipulados en el Protocolo de Kioto, pero aun más estrictos. "Gore” es la política recomendada por Al Gore, según la cual las emisiones deben reducirse en forma drástica, pero gradual, y las disminuciones alcanzarían el 90\% de los niveles actuales antes del año 2050. La quinta y última clase de política se denomina "contención de bajo costo" (low-cost backstop), basada en una tecnología hipotética de bajo costo para eliminar el dióxido de carbono de la atmósfera, o para producir energía sin emitir dióxido de carbono, partiéndose del supuesto de que dicha tecnología estará disponible en una determinada fecha futura. Según Nordhaus, esta tecnología podría incluir "la energía solar de bajo costo, la energía geotérmica, algún tipo de ingeniería climática no invasiva, o árboles genéticamente modificados captadores de carbono".

Puesto que a cada política sometida al DICE se le asigna una vigencia de cien o doscientos años, su eficacia económica debe ser medida en función de una suma agregada de ganancias y pérdidas durante el período completo de modelación. Así pues, la pregunta fundamental desde la óptica

${ }^{1}$ Véase Nicholas Stern, The Economics of Climate Change: The Stern Review (Cambridge University Press, 2007). 
de las políticas públicas es cómo comparar las ganancias y pérdidas actuales con las ganancias y pérdidas dentro de cien años más. Por eso Nordhaus escogió como título "Una cuestión de equilibrio". Si podemos ahorrar M dólares en daños causados por el cambio climático para el año 2110 gastando un dólar el año 2010 para reducir las emisiones, ¿̇a cuánto debe ascender M para que el gasto valga la pena? O, como lo plantearían los economistas, el dinero que se invierte hoy en reducir las emisiones ¿en cuánto podría hacer disminuir o reducir las pérdidas futuras causadas por el cambio climático?

La respuesta convencional de los economistas a esta pregunta consiste en señalar que $\mathrm{M}$ debe ser mayor que el retorno acumulado esperado hasta el año 2110, si el dólar ahorrado en 2010 se invirtiera hoy en la economía mundial a cien años plazo a una tasa promedio de interés compuesto. Por ejemplo, el valor de un dólar invertido a una tasa de interés promedio de $4 \%$ por un período de cien años sería de US\$ 54; ése sería el valor futuro de un dólar dentro de cien años. Así pues, por cada dólar gastado ahora en una determinada estrategia para combatir el calentamiento global, la inversión debe reducir el daño causado por ese fenómeno en un monto que exceda los US\$ 54 dentro de cien años para que reporte un beneficio económico positivo a la sociedad. Si la estrategia de aplicar un impuesto a las emisiones de carbono produce un retorno de sólo US\$ 44 por dólar invertido, los costos de adoptar esa estrategia superarían los beneficios obtenidos. Ahora bien, si el retorno de la estrategia es de US\$ 64 por dólar invertido, las ventajas son claras. Surge la pregunta, entonces, de cuáles serían las estrategias para luchar contra el calentamiento global que logren producir beneficios a largo plazo superiores a sus costos actuales. La agregación de ganancias y pérdidas a lo largo del tiempo debería calcularse considerando una alta tasa de descuento para el futuro remoto.

La elección de la tasa de descuento para el futuro es la decisión más importante que debe adoptar cualquiera que hace planes de largo plazo. La tasa de descuento es la supuesta pérdida porcentual anual en el valor actual de un dólar futuro a medida que avanza el tiempo. El programa DICE permite escoger arbitrariamente la tasa de descuento, pero Nordhaus sólo presenta los resultados para una tasa de descuento de $4 \%$. En este caso se está ciñendo al criterio generalmente aceptado por los economistas. Cuatro por ciento es una cifra conservadora, basada en un promedio de experiencias anteriores de épocas de bonanza y de tiempos difíciles. Nordhaus está fundando sus juicios en el supuesto de que en los próximos cien años la economía mundial exhibirá una mezcla de estancamiento y prosperidad, y que la tasa global de crecimiento promedio se mantendrá en el mismo nivel 
observado durante el siglo XX. Los costos futuros se descuentan porque el mundo del futuro será más rico y se encontrará en mejores condiciones para afrontarlos. Los beneficios futuros se descuentan porque serán una fracción decreciente del patrimonio futuro.

Cuando los costos y beneficios del futuro se descuentan a una tasa de $4 \%$ anual, los costos y beneficios agregados de una política climática aplicada durante todo el período futuro son finitos. Los costos y beneficios más allá de cien años no influyen mayormente en el monto calculado. En consecuencia, Nordhaus toma la cifra de beneficios menos costos durante todo el futuro como una medida del valor neto de la política. Él utiliza esta única cifra, calculada mediante el modelo del DICE de la economía mundial, como un estadístico de mérito para realizar comparaciones entre las distintas políticas. El hecho de representar el valor de una política mediante una sola cifra constituye una burda y excesiva simplificación del mundo real, pero sirve para concentrar nuestra atención en las principales diferencias entre los diferentes cursos de acción.

Éstos son los valores netos de las distintas políticas, calculados mediante el DICE. El valor de cada política se determina calculando su diferencia con la situación en que "todo permanece igual”, sin ningún control de emisiones. Un valor positivo indica que la política es mejor que la situación en que "todo permanece igual", pues el grado de reducción de los daños causados por el cambio climático excede el costo de los controles. Un valor negativo indica que la política es peor que el sistema de "todo permanece igual”, pues los costos son superiores al grado de reducción de los daños. La unidad de valor es un billón de dólares, y los valores se especifican redondeados al billón más cercano. El valor neto del programa óptimo, un impuesto mundial aplicado al carbono que aumenta gradualmente con el tiempo, es +3 , lo cual supone un beneficio de unos US $\$ 3$ billones. El Protocolo de Kioto tiene un valor de +1 con la participación de EE.UU., y de cero sin su participación. La política "Stern" tiene un valor de -15 ; la política "Gore”, de -21, y la política de "contención de bajo costo" de -17.

¿Qué significan estas cifras? Un billón de dólares constituye una unidad difícil de visualizar. Resulta más fácil pensar en ella como US\$ 3 por cada hombre, mujer o niño(a) de la población estadounidense. Es comparable al producto interno bruto anual de la India o de Brasil. Una pérdida o ganancia de un billón de dólares constituiría una perturbación perceptible, pero no arrolladora, en la economía mundial. Una ganancia o una pérdida de US\$ 10 billones representaría una perturbación de grandes proporciones, con consecuencias impredecibles. 
La principal conclusión del análisis de Nordhaus es que las propuestas ambiciosas — como las de "Stern” y "Gore”- resultarían catastróficamente onerosas, y que la alternativa de "contención de bajo costo”, si fuese viable, sería sumamente conveniente, y las demás políticas, incluidas la de “todo permanece igual” y el Protocolo de Kioto, serían sólo moderadamente inferiores a la política óptima. La consecuencia práctica respecto de las políticas destinadas a afrontar el calentamiento global es que deberíamos procurar alcanzar los siguientes objetivos por orden de prioridad: (1) evitar las propuestas ambiciosas; (2) desarrollar la ciencia y la tecnología para encontrar alternativas de contención de bajo costo; (3) negociar un tratado internacional cuyos términos se acerquen tanto como sea posible a los de la política óptima, en caso de que la búsqueda de tecnologías de contención de bajo costo resulte infructuosa; (4) evitar suscribir un tratado internacional que confiera carácter permanente a los términos del Protocolo de Kioto. Estos objetivos son válidos por motivos económicos, independientemente de los pormenores científicos del fenómeno del calentamiento global.

Existe una diferencia filosófica fundamental entre Nordhaus y sir Nicholas Stern. En el capítulo 9 del libro de Nordhaus se explica la discrepancia y se señala por qué Stern defiende una política que Nordhaus considera desastrosa. Stern rechaza la idea de descontar los costos y beneficios futuros cuando se los compara con los costos y beneficios actuales. Siguiendo las prácticas habituales de los economistas y ejecutivos empresariales, Nordhaus considera que el descuento es necesario para alcanzar cualquier equilibrio razonable entre el presente y el futuro. A juicio de Stern, no es ético descontar, pues se discrimina entre las generaciones actuales y futuras. Es decir, Stern estima que al aplicarse el descuento se impone una carga excesiva a las generaciones futuras. Para Nordhaus el descuento es un mecanismo equitativo, pues un dólar ahorrado por la generación actual se transformará en 54 dólares que podrán ser gastados por nuestros descendientes un siglo después.

La consecuencia práctica de la política de Stern sería desacelerar hoy el crecimiento económico de China para mitigar los daños que causará el cambio climático dentro de cien años. Varias generaciones de ciudadanos chinos se verían empobrecidas para que la situación económica de sus descendientes mejore sólo levemente. Según Nordhaus, la desaceleración del crecimiento acabaría siendo en definitiva mucho más costosa para China que el daño climático. En cuanto a la ampliamente debatida posibilidad de que se produzcan efectos catastróficos antes del fin del siglo a causa del 
aumento en el nivel de los océanos, él se limita a señalar que "es improbable que el cambio climático ocasione catástrofes en un futuro inmediato, pero tiene el potencial de provocar graves daños en el largo plazo”. El gobierno chino rechaza categóricamente la filosofía de Stern, mientras que el gobierno británico la acoge con entusiasmo. Nordhaus considera que el Stern Review "adopta una posición altanera de planificador social del mundo, acaso en un intento por atizar las mortecinas brasas del imperio británico".

2. La principal deficiencia del libro de Nordhaus es que no analiza en detalle la alternativa de "contención de bajo costo", que podría dar origen a políticas climáticas mucho más fructíferas que su política óptima. Nordhaus elude este tema porque es economista y no científico. No desea cuestionar los pronunciamientos del Panel Intergubernamental sobre Cambio Climático, un grupo de cientos de científicos designados oficialmente por Naciones Unidas para prestar asesoramiento especializado a los gobiernos. El Panel considera que la ciencia del cambio climático ya es una disciplina establecida y no cree en las contenciones de bajo costo. En cuanto a alternativas que podrían llegar a convertirse en tecnologías de contención de bajo costo, que el autor menciona en el párrafo que cité anteriormente — por ejemplo "la energía solar de bajo costo"-, no es mucho lo que Nordhaus tiene que decir. Señala que "en la actualidad no existe una tecnología de esa naturaleza, y sólo podemos especular al respecto”. La política de "contención de bajo costo" se presenta en sus tablas como una posibilidad abstracta sin entrar en mayores detalles. En ninguna parte se la destaca como una solución práctica al problema del cambio climático.

Vuelvo ahora al gráfico de Keeling, el cual demuestra que existe una estrecha conexión entre la atmósfera y las plantas. Las oscilaciones en el gráfico nos señalan que cada molécula de dióxido de carbono presente en la atmósfera tarda alrededor de doce años en incorporarse a una planta. Por tanto, si podemos controlar lo que las plantas hacen con el carbono, el destino de éste en la atmósfera se encuentra en nuestras manos. Eso es lo que Nordhaus quiso decir cuando se refirió a los "árboles genéticamente modificados captadores de carbono" como una tecnología de contención de bajo costo para hacer frente al calentamiento global. La ciencia y la tecnología de la ingeniería genética no se encuentran aún lo bastante desarrolladas para aplicarlas a proyectos en gran escala. Todavía no comprendemos con suficiente claridad el idioma del genoma como para leerlo y escribirlo con fluidez. Sin embargo, esta ciencia está avanzando a pasos 
agigantados, y la tecnología para leer y escribir los genomas está progresando aun más rápidamente. En mi opinión, probablemente de aquí a veinte años - y casi con certeza dentro de cincuenta años - contaremos con “árboles genéticamente modificados captadores de carbono".

Los árboles captadores de carbono podrían convertir la mayor parte del carbono que absorben de la atmósfera en una sustancia químicamente estable que sepultarían bajo tierra. O bien podrían convertir el carbono en combustibles líquidos o en otras sustancias químicas de utilidad. La biotecnología es una herramienta sumamente poderosa, capaz de sepultar o de transformar cualquier molécula de dióxido de carbono que esté a su alcance. Las oscilaciones del gráfico de Keeling demuestran que una enorme proporción del dióxido de carbono presente en la atmósfera queda cada década a disposición de la biotecnología. Si la cuarta parte de las superficies arboladas del mundo fuera replantada con variedades de las mismas especies que capten carbono, los bosques se podrían preservar como recursos ecológicos y como hábitats para las especies silvestres, y la concentración de dióxido de carbono en la atmósfera se reduciría a la mitad en unos cincuenta años.

Es muy posible que la biotecnología llegue a dominar nuestra vida y nuestra actividad económica durante la segunda mitad del siglo XXI, tal como la tecnología computacional dominó nuestra existencia y nuestra economía durante la segunda mitad del siglo XX. La biotecnología podría llegar a convertirse en un poderoso mecanismo de nivelación, propagando la riqueza por todas las regiones del planeta donde haya tierra, aire, agua y luz solar. Esto no tiene nada que ver con los descaminados esfuerzos que actualmente se están realizando para reducir las emisiones de carbono mediante el cultivo del maíz para convertirlo en combustible de etanol. El programa del etanol no logra disminuir las emisiones y de paso perjudica a los ciudadanos pobres de todo el mundo al provocar un alza en el precio de los alimentos. Una vez que hayamos dominado la biotecnología, las reglas del juego climático van a cambiar radicalmente. Es muy probable que en una economía mundial basada en la biotecnología se haga realidad el sueño de una tecnología de contención barata y respetuosa del medio ambiente, que constituya una alternativa a las fuentes de energía que emiten carbono.

Global Warming: Looking Beyond Kyoto es una compilación de las actas de una conferencia celebrada el 2005 en el Yale Center for the Study of Globalization. La conferencia fue presidida y posteriormente editada por el 
director del Yale Center, Ernesto Zedillo, quien fuera presidente de México entre 1994 y 2000. El libro consta de una introducción a cargo de Zedillo y de catorce capítulos que corresponden a las ponencias de los oradores en la conferencia. Entre ellos está William Nordhaus, cuya colaboración se titula "Economic Analyses of The Kyoto Protocol: Is There Life After Kyoto?”, una crítica más aguda al Protocolo de Kioto que la que podemos encontrar en su propio libro.

El libro de Zedillo cubre un abanico mucho más amplio de temas y opiniones que el libro de Nordhaus, y está dirigido a un círculo más amplio de lectores. Entre otras ponencias se incluye "Is the Global Warming Alarm Founded on Fact?” por Richard Lindzen, profesor de ciencias atmosféricas en el MIT, quien responde a la pregunta con un rotundo no. Si bien no niega la existencia del calentamiento global, Lindzen considera que las predicciones respecto de sus efectos perniciosos constituyen una burda exageración. Escribe el autor:

Las observaciones reales sugieren que la sensibilidad del clima real es mucho menor que la establecida en los modelos computacionales, cuya sensibilidad depende de procesos que a todas luces han sido distorsionados.

En el próximo capítulo, “Antropogenic Climate Change: Revisiting the Facts”, Stephan Rahmstorf, profesor de física oceánica en la Universidad de Potsdam, Alemania, le responde a Lindzen. Rahmstorf resume su opinión sobre los argumentos de Lindzen en una oración: “Todo esto da la impresión de ser absolutamente ajeno a la ciencia climática tal como yo la entiendo, y para ser franco me parece sencillamente ridículo”. Estos dos capítulos entregan al lector un triste panorama de la ciencia climática. Rahmstorf representa a la mayoría de los científicos que creen fervientemente que el calentamiento global constituye un grave peligro. Por su parte, Lindzen es portavoz de la reducida minoría que adopta una postura escéptica. La conversación entre ambos grupos es un diálogo de sordos. La mayoría le responde a la minoría con abierto desprecio.

En la historia de la ciencia ha ocurrido con frecuencia que la mayoría estaba equivocada y se negaba a escuchar a una minoría que, según se demostró más tarde, tenía la razón. Puede que hoy ése sea el caso, como también puede que no. La gran virtud del análisis económico de Nordhaus es que mantiene su validez independientemente de si la postura mayoritaria es acertada o errónea. La política óptima de Nordhaus contempla ambas 
posibilidades. En su introducción, Zedillo resume uno por uno los argumentos de cada colaborador. Mantiene la neutralidad esperable de un presidente de conferencia, y consagra el mismo espacio a Lindzen que a Rahmstorf. Zedillo sólo deja traslucir su propia opinión en una única y breve oración encerrada entre paréntesis: "Puede que el cambio climático no sea el problema mundial más apremiante (algo de lo que estoy convencido), pero de todos modos puede resultar ser el desafío más complejo que el mundo jamás haya afrontado".

Los últimos cinco capítulos del libro de Zedillo fueron escritos por autores de los cinco países a los que más preocupan las políticas sobre el calentamiento global: Rusia, Gran Bretaña, Canadá, India y China. Cada uno de los cinco autores ha sido asesor técnico de gobierno, y cada uno de ellos nos expone la política del respectivo gobierno. Howard Dalton, portavoz del gobierno británico, es el más dogmático. Su párrafo final comienza de la siguiente manera:

El Reino Unido tiene la firme convicción de que el cambio climático constituye una grave amenaza contra el medio ambiente y la sociedad humana, de que es preciso adoptar ahora medidas urgentes en todo el mundo para conjurar esa amenaza, y de que el mundo desarrollado debe demostrar una capacidad de liderazgo para afrontar el cambio climático.

El Reino Unido ya ha tomado posición y considera que se debe ignorar a quienquiera que discrepe de la política gubernamental. Este tono dogmático lo asume también la Royal Society, el equivalente británico de la Academia Nacional de Ciencias de Estados Unidos. La Royal Society publicó en fecha reciente un folleto destinado al público en general, titulado "Climate Change Controversies: A Simple Guide", donde se lee lo siguiente:

En esta obra no se pretende dar respuestas exhaustivas a cada argumento polémico que haya sido planteado por aquellos que procuran distorsionar y socavar los fundamentos científicos del cambio climático y negar la gravedad de las potenciales consecuencias del calentamiento global.

Dicho de otro modo, si usted discrepa de la opinión mayoritaria acerca del calentamiento global, usted es un enemigo de la ciencia. Los autores del folleto parecen haber olvidado el antiguo lema de la Royal Society, Nullius in Verba, que significa "nadie tiene la última palabra”. 
Ninguno de los libros que he leído sobre los aspectos científicos y económicos del calentamiento global, incluidos los dos libros aquí reseñados, logra identificar el quid del problema, que tiene un carácter religioso antes que científico. Existe una religión secular de alcance mundial que podríamos llamar ambientalismo, la cual sostiene que somos administradores de la Tierra, que devastar el planeta con desechos de nuestro estilo de vida inmoderado constituye un pecado, y que para seguir la senda de la virtud hay que vivir con la mayor frugalidad posible. La ética del ambientalismo es inculcada a los niños y jóvenes en los jardines infantiles, en las escuelas y en las instituciones de educación superior de todo el mundo.

El ambientalismo ha reemplazado al socialismo como la principal religión secular. Y la ética del ambientalismo es básicamente correcta. Los científicos y los economistas pueden concordar con los monjes budistas y con los activistas cristianos en cuanto a que la destrucción implacable de los hábitats naturales es algo perverso, y que la celosa protección de las aves y las mariposas es algo bueno. La comunidad mundial de ambientalistas -muchos de los cuales no son científicos- ha adoptado una postura de superioridad moral y está guiando a las sociedades humanas hacia un futuro esperanzador. El ambientalismo, como una religión que infunde esperanza y respeto por la naturaleza, ha llegado para quedarse. Se trata de una doctrina que todos podemos compartir, creamos o no que el calentamiento global es un fenómeno pernicioso.

Desgraciadamente, algunos miembros del movimiento ambientalista también han adoptado como artículo de fe la creencia de que el calentamiento global es la amenaza más grave contra la ecología de nuestro planeta. Ésta es una de las razones por las que los debates sobre este fenómeno han adquirido un tono más agrio y apasionado. Gran parte de la opinión pública ha llegado a considerar como enemigo del medio ambiente a cualquiera que se muestre escéptico respecto de los peligros del calentamiento global. En los tiempos que corren, los escépticos tienen la difícil tarea de convencer a la opinión pública de lo contrario. Muchos de ellos son fervientes ambientalistas, pero les espanta ver cómo la obsesión por el calentamiento global está distrayendo la atención pública de los que consideran son los riesgos más graves e inmediatos para el planeta, incluidos el armamentismo nuclear, el deterioro del medio ambiente y la injusticia social. Independientemente de si resultan estar en lo cierto o equivocados, sus argumentos merecen ser escuchados. 


\section{DEBATE*}

El New York Review of Books recibió numerosas cartas a raíz del artículo “El Problema del Calentamiento Global”, escrito por Freeman J. Dyson. A continuación se reproducen los comentarios enviados por William D. Nordhaus, cuyo libro A Question of Balance: Weighing the Options on Global Warming Policies fue reseñado en el artículo de Dyson. Luego se incluyen las cartas enviadas por dos lectores (Leigh Sullivan y Dimitri Zenghelis) y la réplica de Freeman J. Dyson a esos comentarios.

\section{William D. Nordhaus:}

Discrepo muy poco del comentario que escribió Freeman J. Dyson sobre mi estudio A Question of Balance: Weighing the Options on Global Warming Policies. Sin embargo, la reseña provocó un pequeño estallido de cartas protestando en igual medida por mi estudio y por lo escrito sobre él por Dyson, comentarios que ofrecen una oportunidad de volver a analizar algunas de las controversias más serias.

1. La economía del cambio climático es muy simple. Prácticamente toda actividad involucra de manera directa o indirecta el uso de combustibles fósiles, los cuales emiten dióxido de carbono que es absorbido por la atmósfera. El dióxido de carbono se acumula durante muchas décadas hasta provocar el calentamiento de la superficie, entre muchos otros cambios geofísicos potencialmente perniciosos. Las emisiones de dióxido de carbo-

William D. Nordhaus. William D. Nordhaus. Ph. D. en Economía, MIT. Ocupa la Cátedra Sterling de Economía y es profesor de estudios forestales y del medio ambiente en Yale University. Miembro de la Academia de Ciencias de los EE. UU. y de la Academia Estadounidense de Artes y Ciencias. Investigador del National Bureau of Economic Research y consejero del Brookings Panel on Economic Activity, Washington, D. C. Ha participado en varios comités de la Academia de Ciencias de los EE. UU., entre ellos en el Panel sobre Implicancias de Política del Calentamiento por Gases de Invernadero y en el Comité sobre Implicancias del Cambio Climático Abrupto en la Ciencias y en la Sociedad. Autor de numerosas publicaciones, entre ellas, Invention, Growth and Welfare; Is Growth Obsolete?; The Efficient Use of Energy Resources; Reforming Federal Regulation; Managing the Global Commons; Warming the World.

* Las respuestas y cartas que aquí se reproducen aparecieron en el NYRB, Vol. 55, No 14 (25 de septiembre de 2008). Traducidas al castellano por Alberto Ide para Estudios Públicos y publicadas en esta edición con la debida autorización del NYRB. 
no representan "externalidades", es decir consecuencias sociales de las que no da cuenta el funcionamiento del mercado. Son fallas del mercado, por cuanto la gente no paga el costo actual y futuro de sus acciones.

Si la ciencia económica proporciona un criterio esencial para la formulación de políticas, éste consiste en que debemos corregir esa falla del mercado por la vía de garantizar que toda persona, en cualquier lugar, y por un período indefinido, tenga que afrontar por el uso del carbono el pago de un precio de mercado que refleje el costo social de sus actividades. Los actores económicos — miles de autoridades, millones de empresas, millones de personas, todos los cuales adoptan una infinidad de decisiones cada año - tienen que hacer frente a precios realistas por el uso del carbono para que sus decisiones sobre cuánto consumir e innovar sean adecuadas.

La estrategia más eficiente para retardar o para evitar el cambio climático consiste en aplicar al carbono un impuesto universal y conciliado en forma internacional, que grave el contenido de dióxido de carbono de los combustibles fósiles. El contenido de carbono corresponde a la cantidad total de dióxido de carbono que se emite, por ejemplo, cuando la gente gasta un kilowatthora (kwh) de electricidad o consume 3,5 litros de gasolina.

Para comprender cómo funciona el impuesto al carbono, tomemos como ejemplo el caso de un hogar estadounidense promedio, que cada año consume unos $12.000 \mathrm{kwh}$ de electricidad a un precio de US\$ 0,10 por kwh. Si esta electricidad fuera generada a partir del carbón, las emisiones de carbono llegarían a alrededor de 3 toneladas. Si el impuesto al carbono fuera de US\$ 30 por tonelada, el costo anual por consumo de electricidad generada a partir del carbón se elevaría de US\$ 1.200 a US\$1.290. En cambio, los costos de la energía nuclear o eólica no se verían afectados por un impuesto al carbono, ya que en estas fuentes de energía no se utilizan combustibles emisores de carbono.

El principal objetivo que se persigue al elevar el precio del uso del carbono aplicándole un impuesto es el de entregar poderosos incentivos para reducir sus emisiones. Ello se logrará mediante cuatro mecanismos. En primer lugar, al enviar señales a los consumidores respecto de cuáles bienes y servicios producen altas emisiones de carbono y debieran, por tanto, emplearse con mayor moderación. En segundo lugar, al entregar señales a los productores sobre cuáles insumos utilizan más carbono (como la electricidad generada a partir del carbón) y cuáles utilizan una cantidad menor o nula de carbono (como la electricidad producida por generadores eólicos), lo cual los inducirá a adoptar tecnologías con bajos niveles de emisión de carbono. En tercer lugar, al ofrecer incentivos de mercado a inventores e innovadores para que creen y lancen al mercado productos y procesos con 
bajos niveles de emisión de carbono, que puedan reemplazar a la actual generación de tecnologías.

Por último, el hecho de que el carbono tenga un precio de mercado permitirá reducir la cantidad de información necesaria para llevar a cabo las tres tareas anteriores. Aquellos consumidores éticos, que tienen la esperanza de minimizar su "huella de carbono" (la cantidad de carbono que utilizan), tendrían hoy serias dificultades para calcular con exactitud las emisiones de carbono derivadas de, por ejemplo, viajar en automóvil versus viajar en avión. Al aplicarse un impuesto al carbono, el precio de mercado de todas las actividades en que éste se utiliza aumentaría en la cifra que resulta de multiplicar el impuesto por el contenido de carbono en los combustibles fósiles. Aunque muchos consumidores seguirían ignorando qué porcentaje del precio de mercado es imputable al contenido de carbono, al menos podrían adoptar sus decisiones confiados de estar pagando los costos sociales del carbono que utilizan.

Algunos podrían sostener que un impuesto al carbono no es más que otro lamentable ejemplo de una filosofía económica basada en el principio de “aplicar impuestos y gastar dinero”. Este argumento constituye una interpretación esencialmente errónea de los fundamentos económicos. Aquellos que consumen combustibles fósiles están disfrutando de un subsidio económico: en rigor, están usufructuando del patrimonio común de la humanidad sin pagar el costo de sus actividades. Al aplicarse un impuesto al carbono la eficiencia económica no disminuiría sino que aumentaría, pues corregiría el subsidio implícito al uso de combustibles fósiles.

Con todo, aún subsiste la principal interrogante económica: ¿¿cuál es el precio adecuado del carbono? Actualmente resulta inviable (o por lo menos prohibitivamente oneroso) prevenir el calentamiento global en cualquiera de sus formas; sin embargo, el calentamiento descontrolado supone una grave amenaza para los sistemas humanos y, en especial, para los sistemas naturales. Por tanto, es necesario que logremos establecer un equilibrio entre distintos objetivos en conflicto, como lo son prevenir el cambio climático, mantener el crecimiento económico, evitar riesgos catastróficos y no imponer cargas excesivas a los pobres de las futuras generaciones.

Los cálculos de los daños climáticos incluyen no sólo el impacto en los productos de mercado, como los de las industrias alimentaria y forestal, sino que además consideran las pérdidas ocasionadas en ámbitos distintos al mercado. En los estudios más exhaustivos sobre estos perjuicios se tienen en cuenta factores tales como la mayor intensidad de los huracanes, los efectos que provocan los cambios en la temperatura y las precipitaciones en 
la producción de alimentos, en las actividades recreativas y en los medios de esparcimiento, como también la carga cada vez mayor que representan las enfermedades. Las estimaciones también incluyen correcciones en función del riesgo de eventos poco probables, pero de graves consecuencias, como un abrupto cambio en el clima. Proporcionar estimaciones confiables de muchos impactos futuros de incierta ocurrencia es un desafío estimulante, pero es fundamental que ellos no sean omitidos de los cálculos de los daños causados por el cambio climático.

Mis estudios económicos, citados en A Question of Balance, sugieren que el equilibrio se alcanzaría con un precio del carbono que aumentaría en el curso del tiempo dentro del rango de US\$ 30 a US\$ 50 por tonelada. El límite inferior de este rango es la cifra óptima de rentabilidad puramente económica, mientras que el límite superior impone una restricción adicional al establecer que la temperatura mundial o las concentraciones de dióxido de carbono en la atmósfera no deben exceder los niveles "peligrosos".

Para los Estados Unidos, esos impuestos se traducirían en ingresos tributarios del orden de US\$ 50.000 millones a US\$ 80.000 millones anuales. Para expresarlo en términos de un grupo familiar promedio, un impuesto al carbono de US\$ 30 por tonelada supondría un impuesto a la gasolina que bordearía los siete centavos de dólar por galón; a raíz de lo anterior, el precio de los combustibles fósiles, y de los productos dependientes de aquéllos aumentaría en cerca de 5\%, alza considerablemente inferior a las observadas durante los últimos cinco años.

2. Con ese trasfondo me referiré ahora a dos reparos planteados en el artículo de Freeman Dyson y en las cartas y comentarios que he recibido a raíz del artículo de Dyson: el primero, en relación con la tasa de descuento, y el segundo, referente a las tecnologías de bajo costo para reducir las emisiones de carbono.

Uno de los asuntos de mayor trascendencia en las políticas sobre cambio climático es determinar cuál es la tasa de descuento más adecuada para comparar los costos actuales con los beneficios futuros. Esto es importante porque la sociedad, al disminuir el uso de combustibles fósiles, financiaría hoy el costo de reducir las emisiones, mientras que la mayor parte de los daños evitados se producirán en un futuro lejano. (Recuérdese que, como se señaló antes, los daños corresponden a un concepto global que incluye tanto los impactos en el mercado como los impactos ajenos al mercado y ecológicos, además de los ajustes por riesgos de eventos de graves consecuencias.) Incluso The Stern Review on the Economics of Climate Change, escrito por lord Stern, que adopta una visión pesimista de los 
daños, concluye que durante el próximo siglo los perjuicios ocasionados por el cambio climático serían relativamente leves y que la mayor parte de ellos se observarían después del año 2200. Por consiguiente, necesitamos encontrar una tasa de descuento apropiada para equilibrar los actuales costos de reducción con los leves perjuicios que se producirían dentro de cien o más años.

Podemos ilustrar el tema de la tasa de descuento recurriendo al siguiente ejemplo. Supongamos que un individuo de la más alta calidad moral nos aborda para hacernos la siguiente proposición. Él creará un fideicomiso que dentro de doscientos años devengará a nuestros herederos una utilidad de US\$ 100 millones (reajustados según la inflación), a cambio de que aportemos ahora una determinada suma de dinero, $x$ dólares. El retorno de US\$ 100 millones podría tomar la forma de una disminución en los daños del cambio climático. Alternativamente, podría consistir en hacerlos dueños de un sector de la isla de Manhattan. ¿Cuál es el monto máximo que estaríamos dispuestos a aportar?

Una persona que se guía por la intuición aritmética podría hacer el siguiente razonamiento: "Sé que la suma invertida acumulará intereses y crecerá con el paso del tiempo. Si considero un tipo de interés de 5\% multiplicado por doscientos años, ello arrojaría un total de $1.000 \%$, o un crecimiento por un factor de 10. Así pues, según estos cálculos, para obtener US\$ 100 millones en doscientos años sería necesario invertir US\$ 10 millones ahora. Dicho de otro modo, si presumo que al cabo de ese período el monto invertido aumentará diez veces, hoy no aportaría al fideicomiso más de US\$ 10 millones. Puede que la tasa de interés sea mayor. Si el valor del fondo crece cien veces, mi contribución no debería exceder el millón de dólares”. Nuestra intuición aritmética podría proceder así.

Pero este enfoque, en verdad, ni siquiera se aproxima a la estimación correcta. El cálculo intuitivo pasa por alto el hecho de que el interés es compuesto, vale decir que el interés se paga sobre el monto total y no sólo sobre el monto original. Para calcular el aporte de hoy, un asesor financiero nos aconsejaría considerar los US\$ 100 millones y “descontarlos” al presente utilizando un tipo de interés o una tasa de descuento adecuados. Esa tasa de descuento debería reflejar el monto que podríamos ganar gracias a nuestras inversiones durante el período en cuestión.

Además, en nuestro ejemplo los US\$ 100 millones han sido reajustados según la inflación, de modo que en rigor nos están pagando con bienes futuros. Por este motivo, en el cálculo del valor presente deseamos usar la tasa de descuento en bienes. (Recuérdese, una vez más, que en este análisis estamos utilizando una medida global de los bienes; a su vez, a los bienes 
cuyos precios están subiendo en relación con el promedio se les aplicará una tasa de descuento más baja.) La tasa de descuento de los bienes es aquella que aplicaríamos al convertir a cifras actuales los valores de bienes consumidos en el futuro, actualizados según la inflación. La tasa debería reflejar no sólo la rentabilidad subyacente de las inversiones sociales, sino además factores de riesgo como que la persona "de la más alta calidad moral” pueda ser Freddie Mac (la Corporación Federal de Préstamos Hipotecarios) y no el Tío Sam, o que tal vez no tengamos herederos, o que en el futuro parte de la isla de Manhattan pueda estar cubierta de agua.

Sobre la base de proyecciones y estudios históricos, el rendimiento de la inversión, reajustado según la inflación, ha fluctuado entre 3\% y 6\% anual, dependiendo del período considerado y del riesgo envuelto. En mi modelación he utilizado una tasa de descuento de 4\%. La aplicación de dicha tasa al fideicomiso nos llevaría a proponer un pago actual de $x=\$ 39.204$. Al cabo de doscientos años, una vez que el interés (compuesto) sobre esa suma haya sido pagado, el patrimonio del fideicomiso debería ascender a US\$ 100 millones.

Muchas personas se escandalizarán de que alguien proponga pagar una suma tan exigua. ¿Cómo puede importarnos tan poco el futuro? ¿Acaso con ello no estamos entregando menos de lo que les corresponde a las futuras generaciones? La respuesta es que no se trata de que el futuro nos sea indiferente, sino que contamos con una variada cartera de inversiones productivas en una economía caracterizada por rápidos cambios tecnológicos. En el curso de cien o más años, el poder del crecimiento compuesto transforma diminutas bellotas de inversión en gigantescos robles financieros. Sobre el interés compuesto es siempre útil recordar que, a una tasa de interés monetario de 6\%, los US\$ 26 pagados por Manhattan en 1626 redituarían hoy US\$120.000 millones, monto que equivale aproximadamente al valor de todo el terreno de este valiosísimo sector inmobiliario.

Algunos podrían sostener que es poco ético descontar a futuro y que deberíamos aplicar una tasa de descuento muy baja para calcular el valor presente de bienes futuros o de daños climáticos. Si bien la postura de aplicar una baja tasa de descuento resulta convincente en algunas circunstancias, es poco satisfactoria en el contexto del crecimiento económico previsto en la mayoría de los estudios sobre el cambio climático. Por ejemplo, en The Stern Review se presupone que el ingreso real per cápita global aumentará desde US\$ 10.000 en la actualidad hasta cerca de US\$130.000 dentro de dos siglos. Al mismo tiempo, sobre la base de sus argumentos en favor de la tasa de descuento cercana a cero, en dicho estudio se sostiene 
que hoy deberíamos adoptar medidas urgentes para reducir los daños en el futuro lejano. Aun cuando existen razones atendibles para actuar con celeridad en la prevención del cambio climático, la necesidad de redistribuir el ingreso en beneficio de generaciones futuras no parece ser una de ellas.

El efecto de las bajas tasas de descuento podría ilustrarse mediante un "experimento del pliegue". Supongamos que los científicos descubren que el cambio climático causará un pliegue en el sistema climático — tal vez se trate de una pequeña perturbación en el curso de las corrientes oceánicas- que ocasionará daños equivalentes al $0,1 \%$ del consumo a partir de 2200, tasa que se mantendrá invariable para siempre. ¿Qué monto sería justificado invertir de una sola vez hoy en día para eliminar el pliegue que se formará recién dentro de dos siglos?

Si utilizamos la metodología de descuento del Stern Review, la respuesta es que deberíamos aportar hasta el 56\% de lo que el mundo consume actualmente en un año para eliminar el pliegue. En otras palabras, utilizando la lógica de la baja tasa de descuento, vale la pena provocar ahora, de una sola vez, un impacto de aproximadamente US\$ 30 billones en el consumo para resolver un pequeño problema que comenzará de aquí a dos siglos. Este ejemplo demuestra por qué las implicaciones de utilizar una tasa de descuento cercana a cero - que sugiere que la actual generación tiene la obligación ética de hacer grandes sacrificios hoy en día para evitar daños climáticos relativamente leves que afectarían a futuras generaciones acaudaladas - pueden resultar a todas luces raras ${ }^{1}$.

La lógica del descuento no es que debamos consumir todos nuestros ingresos, como ocurre en la actualidad en los Estados Unidos. Antes bien, yo sugeriría que existen muchas inversiones de alto rendimiento que permitirían mejorar la calidad de vida de las futuras generaciones a nivel nacional e internacional. Esa cartera debería incluir inversiones en sistemas de salud nacionales, en curas para enfermedades tropicales, en educación en todo el mundo, en investigación básica de nuevas fuentes de energía y nuevas tecnologías con bajos niveles de emisión de carbono, y en infraestructura en países devastados por la guerra, como Afganistán. Es difícil sustentar el argumento de que cambios relativamente leves en el consumo en el período posterior al 2200 deberían tener prioridad sobre las necesidades acuciantes de la época actual.

${ }^{1}$ El análisis de la tasa de actualización se desarrolla con mayor detalle en el capítulo 9 de mi libro A Question of Balance (Yale University Press, 2008). Este capítulo también puede encontrarse en nordhaus.econ.yale.edu/Balance_prepub.pdf. 
3. La principal incertidumbre respecto del cambio climático se refiere a la evolución de las tecnologías energéticas a lo largo de un período de cincuenta y más años. Para retardar, e incluso revertir, el cambio climático, nuestras economías necesitarán contar con tecnologías radicalmente novedosas que resulten baratas, que no dañen el medio ambiente y que prácticamente no generen emisiones de dióxido de carbono.

Dyson observa que en mi libro el análisis de las futuras tecnologías se limita a una descripción general de las distintas posibilidades. Él sugiere su propia solución, señalando que "en [su] opinión, probablemente de aquí a veinte años -y casi con certeza dentro de cincuenta años - contaremos con 'árboles genéticamente modificados captadores de carbono'”. Si bien ello podría eliminar una gran cantidad de carbono, tiemblo al pensar en la posibilidad de que amplios sectores de la superficie del planeta vayan a ser destinados a plantaciones de árboles subvencionadas. El peligro es que un programa de forestación subvencionada en gran escala absorbería vastas extensiones de terrenos agrícolas, consumiría enormes cantidades de agua y fertilizantes, y provocaría una crisis alimentaria mundial de proporciones aun mayores que la actual, que ha sido causada en parte por el erróneamente concebido programa estadounidense de subsidio al etanol.

La experiencia histórica nos sugiere que evitemos escoger ganadores en nuestra búsqueda de tecnologías energéticas revolucionarias. La invención de algo nuevo y original es un suceso esencialmente impredecible. ¿Quién podría haber previsto hace un siglo la naturaleza de la electrónica, la biotecnología o las comunicaciones de la era moderna? Lo único cierto es que sólo tenemos una idea sumamente vaga de cuáles podrían ser las tecnologías que dentro de un siglo resguardarán al planeta de los efectos del cambio climático. Debemos abstenernos de pensar que necesitamos un Proyecto Manhattan para desarrollar la tecnología clave en materia climática. Lo más probable es que las nuevas tecnologías inocuas para el clima serán el resultado acumulativo de una multiplicidad de inventos, muchos de los cuales habrán sido ideados por modestos creadores, o provendrán de áreas no relacionadas.

La mejor manera de fomentar el proceso de inventar cosas nuevas y originales consiste en garantizar la existencia de un ambiente económico que propicie la innovación y el emprendimiento. Por sobre todo se requiere que el precio del carbono sea lo suficientemente alto como para que las inversiones en tecnologías con bajas emisiones de carbono reporten un beneficio económico tangible y seguro. Los gobiernos deberían permitir que las tecnologías funcionen en igualdad de condiciones, de modo que ninguna de ellas reciba un trato preferente a través de subsidios, regulaciones o protección de la propiedad intelectual. 
El cambio climático es un fenómeno complejo, sujeto a grandes incertidumbres, y nuestros conocimientos sobre él varían prácticamente a diario. Es improbable que el cambio climático acarree consecuencias catastróficas en un futuro próximo, pero tiene el potencial de ocasionar daños muy graves a largo plazo. Desde un punto de vista económico, hay mucho en juego en el diseño de enfoques eficaces que permitan retardar el calentamiento global y garantizar un ambiente económico favorable a la innovación. El actual enfoque internacional centrado en el Protocolo de Kioto resultará económicamente oneroso y prácticamente no incidirá en el cambio climático. A mi juicio, el mejor enfoque es el que también se caracteriza por su relativa sencillez: aplicar al carbono impuestos conciliados entre las naciones. Por cierto, los economistas y los ecologistas seguirán debatiendo acerca del nivel adecuado del precio del carbono. Pero todos aquellos que creen que estamos frente a un grave problema de alcance mundial coincidirán en que el actual precio — cero- es demasiado bajo y debería corregirse cuanto antes.

\section{Dimitri Zenghelis:}

Como uno de los autores de The Stern Review on the Economics of Climate Change me veo en la obligación de responder a la engañosa reseña — titulada "El Problema del Calentamiento Global”— que Freeman Dyson escribió sobre el último libro de William Nordhaus. La evaluación económica de los efectos de las emisiones de gases de efecto invernadero se basa en: (1) los fenómenos esperados a raíz del aumento de las temperaturas en el planeta, como inundaciones, sequías, migración y conflictos, y (2) los valores asociados a estos fenómenos actuales y futuros. Dyson no identificó las deficiencias del enfoque de Nordhaus en ambos aspectos, las cuales subyacen en su exhortación para reducir las emisiones a límites inferiores a los sugeridos en The Stern Review.

En cuanto a lo primero, Nordhaus subestima de manera sistemática la magnitud de la amenaza que representa el calentamiento global. En un párrafo desconcertante, Dyson escribe:

[Nordhaus] no se ocupa de los aspectos científicos del calentamiento global, ni del detalle de las estimaciones del daño que podría causar [...] Sus conclusiones son en gran medida independientes de los detalles científicos.

Dimitri Zenghelis. Investigador visitante de London School of Economics. Miembro asociado del Royal Institute of International Affairs, Londres. 
Esta observación resulta extremadamente engañosa. El modelo de Nordhaus está determinado por sus supuestos acerca de los aspectos científicos. El problema es que sus proyecciones de los fenómenos no parecen estar en consonancia con los últimos avances científicos. Sostiene, sorprendentemente, que bajo condiciones de aumento descontrolado de las emisiones, el mundo alcanzará el mismo nivel de producción el 2100 que el que habría conseguido el 2099 sin calentamiento global (una "insignificante” diferencia de 2,5\% en el PIB).

El informe más reciente del Panel Intergubernamental sobre Cambio Climático (Intergovernmental Panel on Climate Change, IPCC) indica que, si no adoptamos medidas para reducir las emisiones, existe un considerable riesgo de que en el próximo siglo se produzcan aumentos en la temperatura del planeta superiores a los 5 grados Celsius en relación con la era preindustrial. La última vez que la temperatura de la Tierra experimentó un alza de 5 grados fue alrededor de 35 a 55 millones de años atrás, cuando el paisaje mundial consistía en grandes extensiones cubiertas de bosques cenagosos, y en las cercanías del Polo Norte circulaban caimanes. La última vez que la temperatura de la Tierra descendió en 5 grados fue durante el período glacial, hace unos 10.000 a 12.000 años, cuando gigantescas capas de hielo se extendieron hacia el sur hasta llegar a cubrir la zona que hoy correspondería a Nueva York y a la región central de Inglaterra. El argumento aquí no tiene que ver con los caimanes ni con las capas de hielo, sino con el hecho de que se está redibujando a una velocidad sin precedentes el entorno geográfico que determina cómo y dónde viven las personas. Si durante el siglo venidero la temperatura subiera en 4 grados o más, es probable que el nivel del PIB retrocedería no varios años, sino varios decenios, por lo que millones de personas sufrirían hambre, estrés por falta de agua, migraciones masivas y conflictos.

Aun así, Nordhaus de alguna manera obtiene, a partir de las temperaturas del informe del IPCC, de 3 grados C para 2100 y de 5,3 grados C para 2200, impactos de sólo 2\% y 8\% del PIB, respectivamente. De paso advierte que "los submodelos utilizados en el modelo DICE no pueden entregar los detalles regionales, industriales y temporales generados por los modelos especializados más grandes”, pero es a nivel regional donde efectivamente se calcula el daño para los seres humanos. Aun cuando en el libro hay una referencia a los huracanes, las palabras “inundación” o “sequía” —las principales fuentes de calamidades humanas y ambientales - apenas si se mencionan de pasada. Al minimizar sistemáticamente los riesgos regionales y locales, Nordhaus obtiene impactos económicos muy leves: incluso en 2200 
el PIB mundial retrocede apenas cuatro años con respecto a un punto de referencia sin daños derivados del cambio climático.

En lo referente al segundo aspecto, Dyson analiza la interrogante fundamental de cómo evaluar la serie de fenómenos futuros que se prevén como resultado del aumento en la temperatura del planeta. Él identifica acertadamente el "descuento" como el factor que constituye el quid del problema. Cuando se aplica al consumo, el "descuento" consiste en el proceso de definir el valor presente de una unidad de consumo en cierta fecha futura. La reducción en el valor del consumo de cierta unidad de un año a otro se determina aplicando la correspondiente "tasa de descuento" anual. Desde un punto de vista individual, todos preferimos pan hoy y no mañana, y como estamos conscientes de que en algún momento vamos a morir, descontamos en forma intensiva. Ahora bien, desde la perspectiva de la sociedad, las decisiones de políticas deben sustraerse de la natural impaciencia de los individuos y evaluar las repercusiones de las medidas actuales en las generaciones futuras.

Tradicionalmente ha habido dos motivos por los cuales economistas y filósofos aplican una tasa de descuento a los ingresos futuros de la sociedad. Dyson identifica correctamente el primero y más importante de ellos cuando escribe:

Los costos futuros se descuentan porque el mundo del futuro será más rico y se encontrará en mejores condiciones para afrontarlos. Los beneficios futuros se descuentan porque serán una fracción decreciente del patrimonio futuro.

La pérdida de “felicidad” ocasionada por renunciar a un dólar de nuestro ingreso (por ejemplo, a causa del acceso restringido al agua o por inundaciones costeras) será, por lo general, menor para las personas acaudaladas que para aquellas que a duras penas se ganan la vida. Lo que se intuye es fácil de captar: la pérdida de "felicidad" equivalente a un dólar al que renunciamos será menor para Bill Gates que para un niño hambriento de la calle, pues en el segundo caso podría suponer la diferencia entre la vida y la muerte. Así pues, si las generaciones futuras serán más ricas, entonces no se ve la razón de tener que adoptar medidas ahora para ahorrarles a esas generaciones futuras consecuencias desagradables en lugar de asignar los recursos actuales para emprender en este momento iniciativas que impidan que los pobres sufran hoy esas mismas consecuencias. Por consiguiente, en nuestro cálculo del "valor actual” de los daños causados por el cambio climático debemos “dejar a un lado” los impactos futuros. 
Lo que Nordhaus parece olvidar es que los científicos nos dicen que como secuela de impactos particularmente devastadores, tales como inundaciones en gran escala, sequías generalizadas e intensas tormentas, algunas generaciones serán más pobres que las actuales y se anularán los beneficios del crecimiento económico: evaluar este efecto requeriría aplicar un descuento negativo. La elección que tenemos aquí es entre vías inciertas con implicaciones radicalmente distintas para el planeta. Sin embargo, Nordhaus aplica erróneamente la misma alta tasa de descuento de 5,5\% independientemente de si está evaluando pérdidas leves o devastadoras, con lo cual subvalora sistemáticamente estas últimas ${ }^{1}$. La tasa de descuento de Nordhaus es tan alta que un dólar de consumo perdido el 2150 es valorado en una cifra cercana a sólo 0,02 centavos de dólar perdidos hoy en día, sin importar cuál sea la magnitud de la catástrofe. Al trivializar de esta manera las pérdidas futuras, Nordhaus predetermina su recomendación de actuar en forma más limitada y de que exista un precio de carbono bajo.

El hecho de no aplicar sistemáticamente el concepto de que cada dólar extra produce una cantidad decreciente de "felicidad” adicional arroja también luz sobre las deficiencias de la evaluación que Nordhaus hace de los riesgos. Nosotros asignamos una mayor ponderación a las peores consecuencias precisamente porque nos preocupan más los sucesos en extremo desastrosos. Nuestra aversión a los eventos catastróficos que nos pueden volver más pobres explica por qué la mayoría de nosotros aseguramos nuestras casas, aun cuando sabemos que las compañías aseguradoras ganan dinero con las posibilidades de riesgo contra las cuales nos ofrecen cobertura. Al aplicar una ponderación mayor (esto es, un menor descuento) a los sucesos calamitosos, el enfoque de Stern reflejará automáticamente esta situación, no así el de Nordhaus.

Escribe Dyson: "Stern rechaza la idea de descontar los costos y beneficios futuros cuando se los compara con los costos y beneficios actuales”. Esto es manifiestamente falso. The Stern Review aplicó el descuento basándose precisamente en el principio de que las futuras generaciones pueden ser más ricas o más pobres, como se esbozó anteriormente. De hecho, The Stern Review fue incluso más allá al aplicar un descuento adi-

${ }^{1}$ 5,5\% es la cifra que Nordhaus obtiene formalmente en este modelo para los próximos cincuenta años. También señala que prevé una tasa de descuento promedio de 4\% durante el próximo siglo, pero no aclara cómo llega a efectuar ese cálculo, el cual, según cabe suponer, requeriría una tasa mucho más baja — que en promedio se acercaría al $2,5 \%$ - para la segunda mitad del siglo. Incluso con un descuento continuo de $4 \%$, el bienestar de una persona a mediados del próximo siglo sería valorado en alrededor de 1/40 del bienestar de una persona hoy en día, lo cual inclina la balanza a favor de las políticas que benefician a las actuales generaciones a costa de las generaciones futuras. 
cional para cubrir riesgos extremos, por ejemplo que el mundo sucumba a una lluvia de asteroides, a una plaga o al “Armagedón nuclear”. Si no podemos garantizar la existencia de las futuras generaciones, no parece apropiado valorarlas al mismo nivel que la generación actual, que a todas luces sí existe.

Lo que sí rechazó The Stern Review fue el descuento adicional para discriminar contra las futuras generaciones en función únicamente de sus fechas de nacimiento, proceso conocido como descuento puramente cronológico (pure time discounting). Ésta es la segunda razón para realizar el descuento: el propio transcurso del tiempo. Es diferente al descuento en función de diferencias de ingreso o de aquel basado en el riesgo de futura extinción y que pueden expresarse cuantitativamente, como ocurre en el Stern Review. El descuento puramente cronológico proviene del deseo de un economista de reflejar las preferencias de las personas, quienes se muestran impacientes en muchas de sus actividades cotidianas. Pero el cambio climático es un problema social de tan largo plazo que resulta inapropiado utilizar preferencias telescópicas personales como base para determinar las políticas. ¿Por qué deberíamos ocuparnos del bienestar de las actuales generaciones con un criterio igualitario, y en cambio aplicar un enfoque distinto cuando se trata del bienestar de generaciones que nazcan el próximo año o el año subsiguiente?

Dyson exacerba aun más sus imprecisiones cuando escribe: "Siguiendo las prácticas habituales de los economistas y ejecutivos empresariales, Nordhaus considera que el descuento es necesario para alcanzar cualquier equilibrio razonable entre el presente y el futuro. A juicio de Stern, no es ético descontar, pues se discrimina entre las generaciones actuales y futuras”. Aquí da a entender no sólo que Stern se abstiene de descontar — lo cual es falso_-, sino además que se aleja unilateralmente de las prácticas habituales de los economistas.

Es evidente que Nordhaus en parte propone la discriminación puramente cronológica porque supone que las tasas de retorno del mercado revelan una preferencia social por las compensaciones futuras frente a las actuales $^{2}$. A lo largo de todo un siglo, los teóricos de la economía, desde

2 Técnicamente, para descomponer las tasas de descuento tanto Stern como Nordhaus utilizan lo que se conoce como ecuación de Ramsey. La diferencia radica en que Stern estructura su tasa de descuento a partir de primeros principios para obtener una cifra de descuento acumulado; Nordhaus procede a la inversa. Comienza por la respuesta $-5,5 \%$ que deriva de los mercados - y opera hacia atrás para llenar los términos de la ecuación a fin de "explicar" esa cifra. Sólo puede hacerlo aplicando un descuento puramente cronológico improbablemente alto, ya que los términos que sólo se relacionan con los diferenciales de ingresos no lo llevarían a obtener un 5,5\% con supuestos razonables. 
Marshall y Pigou hasta Arrow y Mirrlees, han reconocido que este vínculo lógico es erróneo, excepto bajo circunstancias improbables, como que todos los mercados funcionen a la perfección y que todos los consumidores se encuentren representados ${ }^{3}$. Otros economistas, desde Ramsey hasta Solow, Keynes y Sen, rechazan el descuento puramente cronológico por considerarlo un mecanismo arbitrario carente de una base ética que pueda inspirar la elección de políticas públicas a largo plazo ${ }^{4}$. Es Nordhaus ${ }^{5}$, y no Stern $^{6}$, quien se aleja de "las prácticas habituales" de algunos de los más distinguidos economistas y filósofos.

Por último, si efectivamente invirtiésemos de manera convencional a tasas de mercado y más adelante intentáramos "mitigar” los daños ambientales futuros, los costos de la acción subirían bruscamente porque la acumulación de gases de efecto invernadero — según las actuales estimaciones

${ }^{3}$ De hecho, los mercados de capital están plagados de distorsiones. Cameron Hepburn en "Discounting Climate Change Damages: Working Note for the Stern Review" (Oxford University, 2006), al igual que Simon Dietz, Cameron Hepburn y Nicholas Stern en "Economics, Ethics, and Climate Change" (London School of Economics, 2007), sostienen que es difícil encontrar algún mercado que pueda entregar respuestas claras a la siguiente pregunta: “¿de qué manera nosotros, como generación, valoramos los beneficios asociados a iniciativas colectivas destinadas a proteger el clima por generaciones de aquí a cien o más años?”. Para un análisis más detallado, el lector es remitido a la reciente Conferencia Ely ofrecida por lord Stern durante el ciclo de reuniones de la American Economic Association celebrado en enero de 2008 (American Economic Review, Vol. 98, $\mathrm{N}^{\circ}$ 2, mayo de 2008).

${ }^{4}$ Véase, por ejemplo, Frank Ramsey, “A Mathematical Theory of Saving”, en The Economic Journal, Vol. 38, No. 152 (diciembre de 1928), pp. 543-559; Arthur Pigou, The Economics of Welfare, cuarta edición (Londres: Macmillan, 1932), pp. 24-25; Roy Harrod, Towards a Dynamic Economics (Londres: Macmillan, 1948), pp. 37-40; Robert Solow, "The Economics of Resources or the Resources of Economics", en American Economic Review, Vol. 64, No. 2 (mayo de 1974), pp. 1-14; James Mirrlees y Nicholas Stern, "Fairly Good Plans”, en Journal of Economic Theory, Vol. 4, No. 2 (abril de 1972), pp. 268-288; Sudhir Anand y Amartya Sen, "Human Development and Economic Sustainability", en World Development, Vol. 28, No. 12 (2000), pp. 2029-2049.

${ }^{5}$ El profesor Mohammed Dore, del Laboratorio de Cambio Climático de la Universidad de Brock, en Saint Catharines, Ontario, Canadá, lo plantea de manera sucinta en A Question of Fudge: Professor Nordhaus on Global Policy for Climate Change (en prensa), cuando señala: "resulta extraño que toda una tradición de teóricos de la economía del bienestar — desde Ramsay y De Graaf hasta Mirrlees - no haya influido en lo más mínimo en Nordhaus, quien sostiene que el cambio climático es la madre de todos los bienes públicos, iy luego se olvida del bien público en sus políticas óptimas!”.

${ }^{6}$ Lord Stern ejerce actualmente la cátedra IG Patel de Economía y Gobierno en la London School of Economics, y ha dedicado toda una vida de trabajo a la economía pública. Ha publicado más de quince libros y cien artículos, y entre los años 2000 y 2003 fue economista principal del Banco Mundial. Recientemente fue elegido presidente de la European Economic Association por economistas académicos europeos. Asimismo asesora a una larga lista de líderes mundiales. 
del IPCC — sería tan grande que podría provocar cambios peligrosos e irreversibles en el clima. Asimismo, los consumidores asignarían un mayor valor al medio ambiente, de modo que compensarlos por un determinado deterioro ambiental resultaría más costoso de lo que es ahora.

Los intentos por cuantificar los argumentos a favor de tomar medidas sobre el cambio climático deben considerar la completa gama de riesgos determinados por los últimos descubrimientos científicos y utilizar un enfoque económico que refleje sistemáticamente dichos riesgos ${ }^{7}$. Es lo mínimo que se merecen las generaciones futuras. Desgraciadamente, el enfoque que adoptan el artículo de Dyson y el libro de Nordhaus no logra reflejar esos riesgos completamente.

\section{Leigh Sullivan:}

En el excelente comentario que Freeman Dyson escribió sobre los libros de William Nordhaus y Ernesto Zedillo dedicados al calentamiento global se les reprocha a los autores no haber considerado los métodos de “contención de bajo costo” como una política viable para combatir el cambio climático. Dyson arguye con elegancia que el desarrollo genético de “árboles captadores de carbono", capaces de "convertir la mayor parte del carbono que absorben de la atmósfera en una sustancia químicamente estable que sepultarían bajo tierra”, pondría en nuestras manos el destino del carbono atmosférico que causa el calentamiento global. Dyson considera probable que esa vegetación captadora de carbono esté disponible dentro de los próximos veinte años, y tiene la certeza de que ello ocurrirá de aquí a cincuenta años. Para entonces, nuestra comprensión del genoma vegetal debería haber avanzado lo suficiente como para poder manejar los procesos bioquímicos de las plantas.

Sin embargo, quisiera señalar que no es preciso que esperemos ni siquiera dos décadas para usar la vegetación “captadora de carbono” a fin de mitigar los efectos del calentamiento global. Hoy en día contamos con

${ }^{7}$ Véase Simon Dietz, Chris Hope, Nicholas Stern y Dimitri Zenghelis, "Reflections on the Stern Review (1): A Robust Case for Strong Action to Reduce the Risks of Climate Change”, en World Economics, Vol. 8, No. 1 (2007), pp. 121-168; como asimismo Dennis Anderson, Simon Dietz, Nicholas Stern, Chris Taylor y Dimitri Zenghelis, "Right for the Right Reasons: A Final Rejoinder on the Stern Review", en World Economics, Vol. 8, No. 2 (2007), pp. 229-258.

Leigh Sullivan. Director de Southern Cross GeoScience, Southern Cross University, Lismore, Nueva Gales del Sur, Australia. 
los conocimientos biotecnológicos necesarios (véase, por ejemplo, Jeffrey F. Parr y L. A. Sullivan, "Soil Carbon Sequestration in Phytoliths", en Soil Biology and Biochemistry, Vol. 37 (2005), pp. 117-124). Durante varios milenios las comunidades de vegetación natural, al atrapar, a medida que crecen, el carbono dentro de esferas microscópicas de sílice presentes en sus hojas, han estado eliminando cada año, de un modo seguro, cientos de millones de toneladas de dióxido de carbono de la atmósfera. Dichas esferas de sílice contenidas en las plantas - llamadas "fitolitos" o "piedras vegetales"- son sumamente durables y persisten mucho después de que otros compuestos de carbono de las plantas se han desintegrado y retornado a la atmósfera. Como resultado de lo anterior, el carbono atrapado dentro de estos fitolitos es muy estable frente a la descomposición.

Muchos de nuestros principales cultivos agrícolas (por ejemplo, los basados en gramíneas, como el trigo o la caña de azúcar) tienen una capacidad para captar carbono muy superior a la de estas comunidades vegetales naturales (véase, por ejemplo, www.gold schmidt2007.org/abstracts/ A985.pdf). Ello le confiere a la agricultura el potencial para desempeñar un importante papel en el control del nivel de carbono atmosférico. Es más, los distintos cultivares dentro de especies de monocultivo también varían considerablemente en cuanto a su capacidad para secuestrar el carbono en el sílice vegetal, por lo que la adopción de esta solución biotecnológica de muy bajo costo involucra sólo mínimos cambios en el actual uso de la tierra. Lo anterior nos lleva a la sorprendente conclusión de que las decisiones relativamente sencillas sobre qué cultivar, que día a día adoptan los agricultores en sus campos y dehesas, tienen un enorme impacto acumulativo en la cantidad de carbono secuestrado de manera segura en los suelos agrícolas de todo nuestro planeta.

En suma, no tenemos que esperar decenios a que el desciframiento del genoma vegetal conduzca al desarrollo de una vegetación captadora de carbono que permita moderar el cambio climático, pues nuestro actual nivel de comprensión del genoma vegetal resulta suficiente. De algún modo contra toda lógica, dados los frecuentes debates políticos en torno al imperativo de mitigar el cambio climático, uno de los principales obstáculos que impiden la adopción de vegetación captadora de carbono es la falta de políticas a nivel nacional e internacional que incentiven a los dueños de la tierra a escoger y explorar cultivos captadores de carbono más eficaces. 


\section{Réplica de Freeman J. Dyson:}

1. A todos los autores: Estas cartas representan el contenido de muchas otras, algunas de las cuales manifiestan una abierta discrepancia y otras manifiestan acuerdo, no sin algunas reservas, con lo señalado en mi artículo. Quisiera pedir disculpas a las personas cuyas cartas no han sido reimpresas en este espacio. Si bien mis réplicas están dirigidas a aquellos cuyas respuestas sí son reproducidas en estas páginas, resultan igualmente aplicables a los demás. Como científico sé que todas las opiniones, incluida la mía, pueden estar equivocadas. Expreso mis puntos de vista con firmeza porque creo que son correctos, pero en ningún caso tengo pretensiones de infalibilidad. Haciendo mías las palabras de Oliver Cromwell, los insto a considerar la posibilidad de estar equivocados. Un principio que todos deberíamos aceptar.

2. A Dimitri Zenghelis: Su carta corresponde a una enunciación de la doctrina Stern, con la que esencialmente estoy en desacuerdo, y respecto de la cual remito a los lectores a los argumentos expuestos por William Nordhaus. La doctrina Stern se basa en una visión sombría del futuro. La principal razón por la que me opongo a ella es que el primer decenio del siglo XXI ha alterado de manera irreversible el curso de la humanidad y la ha encaminado hacia un futuro esperanzador. En este decenio, China e India han decidido que el dinero es más importante que la ideología. Decidieron enriquecerse. Se trata de una resolución similar a la adoptada por Gran Bretaña en el siglo XVIII. Los gobernantes de Gran Bretaña decidieron que el dinero era más importante que la religión.

El trasfondo intelectual de estas decisiones se describe en el libro The Passions and The Interests, escrito por el economista Albert Hirschman, quien por muchos años fue mi colega en el Instituto de Estudios Avanzados de Princeton. En el siglo XVIII, "las pasiones” se referían a las creencias teológicas que motivaron las guerras religiosas libradas en el siglo XVII. En el siglo XXI, "las pasiones” aluden a las creencias ideológicas que inspiraron las guerras nacionalistas del siglo XX. A lo largo de todos estos siglos, "los intereses” fueron la supremacía del comercio y las manufacturas que enriquecen a los países.

La decisión de enriquecerse no significó que la pobreza desapareciera de Gran Bretaña, o que vaya a extinguirse en China y en la India. Nos indica que China y la India, al igual que Gran Bretaña tres siglos atrás, se transformarán en países ricos que ejercerán una influencia preponderante sobre el resto del mundo. Asia, que constituye el centro de gravedad de la población mundial, de ahora en adelante será un continente más rico que 
pobre. Por eso la tasa de descuento de 4\% anual prevista por Nordhaus para la economía mundial en el siglo XXI parece razonable.

La diferencia entre la visión del futuro de lord Stern y la mía es la diferencia entre la pasión y el interés, entre el estancamiento que se impone ideológicamente y el libre crecimiento. Mientras a lord Stern le gustaría que nos sometiéramos a sus pasiones, yo quisiera que obedeciéramos a nuestros intereses. No me parece que el estancamiento, que resultaría de las onerosas medidas de control propuestas por lord Stern para reducir las emisiones de gases de efecto invernadero, tenga sentido ni en el ámbito de la economía ni en el de la climatología. Tanto en las sociedades humanas como en los sistemas climáticos, los períodos de estancamiento siempre han alternado con períodos de cambios drásticos. Un futuro de permanente estancamiento no es factible ni deseable. Hasta no hace mucho China había padecido un estancamiento que se extendió por varios siglos, y ahora, con toda razón, está resuelta a dejar de sufrir penurias. Les recomiendo prestar atención a la última oración del libro de Hirschman: "Esto es probablemente lo único que podemos pedirle a la historia, y en particular a la historia de las ideas: no zanjar el asunto, sino elevar el nivel del debate”.

3. A William Nordhaus: Estoy complacido de que concuerde con la mayor parte de lo señalado en mi comentario y que no estime que sus opiniones han sido burdamente tergiversadas. Su principal reparo, formulado en la última sección de su carta, es que yo sólo consideré el cultivo en gran escala de árboles captadores de carbono como una posible "alternativa de contención de bajo costo” para contrarrestar los efectos del calentamiento global. Usted se opone a las plantaciones de esos árboles en gran escala porque invaden tierras agrícolas y obstaculizan la producción de alimentos, amén de producir otros efectos ecológicos nocivos. Decidí referirme al tema de los árboles captadores de carbono porque representan una de las posibles alternativas que usted mencionó en la página 19 de su libro. Opté por suponer que sólo la cuarta parte de la vegetación terrestre sería sustituida por variedades captadoras de carbono de las mismas especies, de manera que los reemplazos pudieran efectuarse sin invadir tierras agrícolas o bosques con valor comercial. La vegetación reemplazada podría corresponder a extensiones de chaparrales y a tierras agrícolas abandonadas, que en la actualidad no están destinadas a la producción de alimentos o de madera. También observé que en los reemplazos con árboles captadores de carbono se mantendría la misma diversidad ecológica y el mismo hábitat para la vida silvestre asociados a las especies sustituidas. Esta intervención no se asemejaría a la iniciativa por la que las plantaciones de maíz son 
desviadas desde la producción de alimentos hacia la producción de etanol por causa de los subsidios estatales a este combustible, de los cuales usted abomina con toda razón.

Dos posibles "tecnologías de contención de bajo costo" que no mencioné en mi reseña, ya que usted no aludió a ellas en su libro, son el fitoplancton captador de carbono en los océanos y la inducción de nevadas en la Antártida oriental. Cualquiera de las dos podría ser una alternativa preferible a la plantación de árboles captadores de carbono. Fitoplancton es el nombre con que oficialmente se designa a las plantas flotantes microscópicas que viven en la capa oceánica iluminada por el sol. El fitoplancton captador de carbono podría ser modificado genéticamente para absorber el dióxido de carbono del océano y convertir el carbono en pequeños gránulos o "pellets" que se hundirían en el fondo oceánico, donde permanecerían indefinidamente. Ellos eliminarían el dióxido de carbono del océano, el cual sería reemplazado por dióxido de carbono proveniente de la atmósfera. El fitoplancton modificado genéticamente podría ser más barato y políticamente más aceptable que los árboles modificados genéticamente. El fitoplancton podría cumplir, asimismo, otras dos útiles funciones: aumentar la población de peces de valor comercial y disminuir el grado de acidez del océano.

La inducción de nevadas en la Antártida oriental sería un buen método para impedir que el nivel de los océanos, que ha estado aumentando desde fines del período glacial más reciente, hace 12.000 años, continúe elevándose. Si bien la mayor parte de este fenómeno no es atribuible a actividades humanas, un catastrófico ascenso adicional de 15 metros sería una de las posibles consecuencias más desfavorables de las actividades humanas durante los próximos dos siglos. Una subida de 15 metros sería el resultado de un completo derretimiento del hielo en Groenlandia y en la Antártida occidental originado por el calentamiento global. Ese derretimiento es improbable pero no imposible. Afortunadamente, la Antártida oriental es una zona mucho más fría y vasta que Groenlandia y que la Antártida occidental, y su casquete glaciar no está en peligro de derretirse. Un anticiclón permanente de altas presiones sobre la Antártida oriental permite que el aire sobre el continente se mantenga seco y las nevadas sean escasas. Ese mismo anticiclón mantiene un intenso flujo de aire húmedo desde el Oeste, el cual circula por el océano Antártico.

Para inducir la caída de nieve sobre la Antártida oriental es preciso que traslademos el núcleo del anticiclón desde el centro del continente hacia los bordes del mismo. Ello podría lograrse desplegando una gigantesca batería de cometas o globos sujetos con amarras, de modo de bloquear en un solo sector el flujo de aire desde el oeste. Este bloqueo provocaría un 
alza local de la presión atmosférica. El núcleo del anticiclón se trasladaría hacia la zona de bloqueo, y una fracción de los vientos del Oeste que circulan en el lado opuesto de la Antártida se desplazaría desde el océano hacia el continente. Las cometas o los globos también podrían utilizarse para generar enormes cantidades de energía eléctrica que se aprovecharía en otros proyectos de ingeniería planetaria. Con generadores eléctricos o sin ellos, el flujo de aire húmedo desde el mar a una velocidad de pocos kilómetros por hora produciría nevadas cuya intensidad promedio equivaldría a unos cuantos metros de hielo anuales sobre la superficie de la Antártida oriental. Todo el hielo añadido al continente sería sustraído de las aguas oceánicas. Esa cantidad de nieve sería suficiente para contrarrestar el aumento en el nivel de los océanos derivado del derretimiento total de Groenlandia y de la Antártida occidental dentro de dos siglos. Año a año podríamos aumentar o disminuir la altitud de los cometas y ajustar el flujo del aire húmedo por todo el continente para así mantener los océanos en un nivel preciso y constante.

El fitoplancton captador de carbono y la inducción de nevadas constituyen proyectos extravagantes. Al igual que los sueños acariciados por otras ingeniosas mentes en el pasado, probablemente serán reemplazados por ideas mejores y tecnologías más novedosas mucho antes de que resulten necesarios. Ellos ilustran el principio general de que si permitimos que continúe el crecimiento económico, siempre dispondremos de antídotos hasta para las consecuencias más desastrosas del cambio climático. El futuro de la tecnología desde ahora hasta más allá de cincuenta años es completamente impredecible. Ésa es otra razón de peso para aplicar a los costos de los desastres futuros la tasa de descuento de $4 \%$ anual que usted recomienda.

4. A Leigh Sullivan: Me complace enterarme de que las plantas captadoras de carbono ya existen y no hay que inventarlas. Sin embargo, ni en su carta ni en los trabajos que usted cita se señala la cantidad de carbono que pueden captar dichas plantas. El quid del asunto es de carácter cuantitativo. La cantidad de carbono secuestrada por las comunidades vegetales naturales es ampliamente menor que la cantidad de carbono que absorben. Aun cuando mis conocimientos sobre agricultura o sobre fisiología vegetal son muy rudimentarios, mi estimación es que los más eficaces captadores naturales de carbono se quedan cortos por un factor de 10. Si este cálculo resulta acertado, entonces todavía se requiere avanzar mucho más en el estudio de la ingeniería genética antes de que se pueda contar con especies capaces de captar el carbono en cantidades suficientes para contrarrestar 
los efectos del uso de combustibles fósiles. Esta observación es igualmente válida para el fitoplancton captador de carbono. Para neutralizar las consecuencias del empleo de combustibles fósiles, el fitoplancton también debe secuestrar un alto porcentaje del carbono que absorbe.

5. A todos los autores y lectores: Les agradezco que me hayan brindado la oportunidad de analizar el problema del calentamiento global sin necesidad de entrar en polémicas ni en acusaciones. Si se pretende hallar soluciones razonables para los problemas, es preciso escuchar todas las opiniones y tratar a todos los participantes con respeto. 